\title{
Erratum to: On the spectrum of the Page and the Chen-LeBrun-Weber metrics
}

\author{
Stuart J. Hall · Thomas Murphy
}

Published online: 12 February 2015

C) Springer Science+Business Media Dordrecht 2015

\section{Erratum to: Ann Glob Anal Geom (2014) 46:87-101 DOI 10.1007/s10455-014-9412-6}

Page 94 The linear functions that define the moment polytope associated to the ChenLeBrun-Weber metric are given by:

$l_{1}(x)=x_{1}, l_{2}(x)=x_{2}, l_{3}(x)=\left(a-x_{1}\right), l_{4}(x)=\left(a-x_{2}\right), l_{5}(x)=\left(1+a-x_{1}-x_{2}\right)$.

Page 94 The constant $c_{1}$ that determines the scalar curvature $s_{k}(x)=c_{1}\left(x_{1}+x_{2}\right)+c_{2}$ is given by:

$$
c_{1}=\frac{48\left(1-a^{3}\right)}{a^{6}+6 a^{5}+9 a^{4}+4 a^{3}-3 a^{2}-6 a+1} .
$$

The constant $c_{2}$ is given correctly. Though the constant $c_{1}$ was stated incorrectly in the paper, all the numerical calculations were made with the correct constants.

Page 95 The integral in the third line of mathematics from the bottom of the page should read

$$
\frac{1}{18} \int_{M}\left(4 \Lambda s_{k}^{-6}-s_{k}^{-3}\right) \mathrm{d} V_{k}
$$

The online version of the original article can be found under doi:10.1007/s10455-014-9412-6.

\section{S. J. Hall ( $\square)$}

Department of Applied Computing, University of Buckingham, Hunter St., Buckingham MK18 1G, UK

e-mail: stuart.hall@buckingham.ac.uk

T. Murphy

Department of Mathematics, California State University Fullerton,

800 N. State College Blvd., Fullerton, CA 92831, USA

e-mail: tmurphy@fullerton.edu 